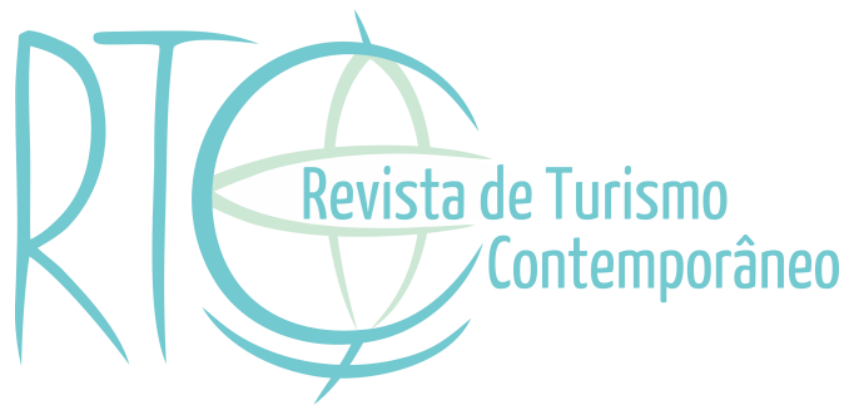

\title{
Ensino superior em hotelaria: relação entre formação profissional e prática no mercado de trabalho
}

High education in hospitality: relationship between professional training and practice in the labor market

Paula Dutra Leão de Menezes

Professora do Departamento de Turismo e Hotelaria da Universidade Federal da Paraíba UFPB, João Pessoa/PB, Brasil

E-mail: leaopaula@ccta.ufpb.br

\section{Amanda Lins Silva}

Graduanda em Hotelaria pela Universidade Federal da Paraíba - UFPB, João Pessoa/PB, Brasil

E-mail: amandalins.als@gmail.com 


\section{RESUMO}

O tema educação e trabalho no ensino superior vêm se aproximando em decorrência do reconhecimento das questões inerentes a formação profissional recebida e a adequação com o cotidiano de trabalho. Dessa forma, destaca-se a necessidade de compreender se a formação recebida pelos bacharéis em hotelaria está cumprindo seus propósitos e, ao mesmo tempo, fornecer subsídios para a entendimento da relação entre formação profissional e prática profissional. O presente estudo analisou a relação entre a formação do profissional e prática de mercado de trabalho na perspectiva dos egressos do curso de hotelaria da Universidade Federal da Paraíba. Para tanto, realizou-se uma pesquisa qualitativa descritiva. Para a coleta de dados realizou-se entrevista de Grupo Focal com egressos do curso de hotelaria da UFPB que estão atualmente inseridos no mercado de trabalho em hotelaria. Os egressos expuseram que o curso melhorou com o novo projeto pedagógico de curso e, que atualmente, está caminhando para encontrar uma identidade e avaliam que a transferência do curso do campus de Mamanguape para João Pessoa, bem como a criação do Departamento de turismo e Hotelaria contribuiu para a formação de uma identidade. Segundo os entrevistados faltou na formação mais aspectos relacionados a parte operacional e, sobretudo a prática, elencando como o ponto mais negativo a ausência de laboratórios no curso. Em relação a formação profissional e o mercado de trabalho afirmaram que foi distante, e explicaram que o setor está em crise, que são muitas as mudanças no contexto do mercado e das novas tendências.

Palavras-chave: Ensino Superior. Formação Profissional. Hotelaria.

\section{ABSTRACT}

The theme of education and work in higher education has been approaching due to the recognition of the issues inherent to the professional training received and the adequacy with the daily work. Thus, it is highlighted the need to understand whether the training received by the staff in hospitality is fulfilling its purposes and, at the same time, provide subsidies for understanding the relationship between vocational training and professional practice. The present study analyzed the relationship between professional training and labor market practice from the perspective of graduates of the hospitality course at the Federal University of Paraíba. For this, a descriptive qualitative research was carried out. For data collection, a Focal Group interview was conducted with graduates of the hospitality course at UFPB who are currently inserted in the hospitality labor market. The graduates exhibited that the course improved with the new pedagogical project of the course and, currently, is moving to find an identity and evaluate that the transfer of the course from the campus of Mamanguape to João Pessoa, as well as the creation of the Department of Tourism and Hospitality contributed to the formation of an identity. According to the interviewees, more aspects related to the operational part and, above all the practice, the absence of laboratories in the course as the most negative point. In relation to vocational training and the labor market, they stated that it was distant, and explained that the sector is in crisis, that there are many changes in the context of the market and new trends.

Keywords: Higher Education. Professional Training. Hospitality. 


\section{INTRODUÇÃO}

A conjuntura da expansão educacional no mundo e no país, ocorre em um cenário social de mudança na estrutura do capitalismo, dos processos de produção, da organização do trabalho, bem como, da formação profissional. A competitividade, a busca pela qualidade e sobrevivência das empresas passam a ser o centro das transformações e o conhecimento tornase também mercadoria chave na determinação de vantagem competitiva.

O tema educação e trabalho vêm se aproximando em decorrência do reconhecimento que a educação pode vir a contribuir para o desenvolvimento econômico e pelo reconhecimento de que as pessoas que possuem formação profissional adequadas podem estar mais habilitados a lidar com a complexidade crescente do sistema produtivo. Nesse aspecto, em estudo sobre as representações sociais do bacharel em Turismo, Menezes e Teixeira (2020) analisam que todo profisssional visa à realização profissional, bem como a empregabilidade e explicam que é necessário compreender quem são esses profissionais e se a sua formação tem percorrido o caminho que levará a sua empregabilidade. Com isso, identifica-se a necessidade de averiguar como a formação dada a esses profissionais se relaciona com esses aspectos.

A empresa hoteleira é um dos segmentos primordiais para o desenvolvimento do turismo em qualquer região. Constituindo-se, assim, um equipamento que compõe a infraestrutura turística. Por sua vez, o hóspede está cada vez mais exigente e para melhor atender esses clientes os empresários devem preparar seus colaboradores (funcionários) para o bom desempenho de suas funções e mantendo-os sempre em condições de melhor executá-las, para tanto torna-se fundamental investir na formação profissional.

No que se refere à produção científica na área, segundo Rocha, Mesquita, Meira e Milhomem (2019) no período entre 2008 e 2017 foram publicados 115 artigos em 21 periódicos nacionais, sendo que 252 pesquisadores participaram da elaboração destas publicações e aproximadamente $59 \%$ das instituições identificadas são universidades públicas federais. Os autores identificaram que as palavras-chave mais utilizadas nos artigos foram turismo, gestão e serviço e com frequência um pouco menor, aparecem os verbetes: inovação, hospitalidade e qualidade. De sorte que pesquisas sobre ensino superior em hotelaria e formação e atuação profissional não se apresentaram como objeto de estudo apesar da importância.

A premissa que sustenta essa pesquisa é qual a relação entre a formação profissional em hotelaria e a prática de mercado de trabalho. Nesse entendimento, é importante analisar a relação entre a formação do profissional e prática de mercado de trabalho na perspectiva dos egressos do curso de hotelaria da Universidade Federal da Paraíba. 
A justificativa para o presente estudo é compreender e avaliar se a formação recebida pelos bacharéis em hotelaria está cumprindo seus propósitos na formação desse profissional e, ao mesmo tempo contribuir com subsídios para o entendimento da relação entre formação profissional e inserção no mercado de trabalho.

\section{ENSINO SUPERIOR NO BRASIL}

As transformações ocorridas no trabalho e a democratização do ensino universitário levaram uma nova demanda de alunos para o ensino superior e, por sua vez, as universidades e o ensino tiveram que reconfigurar as bases de atuação. Nesse contexto, insere-se no ensino superior a questão da educação e trabalho.

Nesse aspecto, as políticas educacionais implementadas no Brasil a partir da década de 1990 são concebidas em um cenário neoliberal em sintonia com os processos de acumulação capitalista. De acordo com Diniz e Goergen (2019) a educação superior brasileira está lastreada em termos jurídicos por dispositivos constitucionais regulamentados por leis ordinárias que regem o sistema de ensino, em termos nacionais, além de acordos internacionais, tais como a Declaração Mundial sobre Educação Superior no Século XXI, que em termos internacionais resinificam a graduação conferindo-lhe novas missões e reforçando a ideia de educação ao longo da vida, condizente com as finalidades propostas pela Lei de Diretrizes e Bases - LDB, embora estreitamente associada com a ideia utilitarista de educação, como motor para o desenvolvimento econômico.

Mancebo, Silva Júnior e Schugurensky (2016) analisam como ocorreu esse processo no Brasil entre os anos de 1995 a 2013. A primeira fase teve como base econômica a demanda imposta ao país em face de sua aderência à globalização, gerada pelo predomínio do capital financeiro e tem seu ápice em 1995. A segunda fase, foi marcada pela edição de inúmeras legislações, que afetaram as mais diversas instâncias, órgãos estatais e instituições em geral e, em particular, as Instituições de Ensino Superior (IES). Os traços que passam a ser perseguidos, de um modo bem geral, na educação superior brasileira são: a pesquisa aplicada; cursos mais rápidos, inclusive apoiados em novas tecnologias de informação e comunicação; processos avaliativos ou de regulação calcados em resultados, entre outros. Adicionalmente, cabe destacar a gradativa perda da autonomia universitária, diretamente relacionada à emergência de uma heteronomia de gestão e de uma nova relação entre a universidade e o setor empresarial, que começa a ter curso. Os autores explicam que todas essas mudanças já podiam ser observadas nos países de economia central, tanto nos países da União Europeia, especialmente com o Processo de Bolonha (acordo assinado em 1999), mas também se apresentavam no Canadá e, 
principalmente, nos Estados Unidos da América. E a terceira, no período entre 2004 e 2013 com a continuação da reforma por meio de um grande número de leis, decretos e portarias, regulando o trabalho docente, os currículos, as avaliações, etc.

Dessa forma, as políticas educacionais encontram-se relacionadas ao mercado e as suas demandas e, nesse aspecto, entram em cena as normativas que orientam o ensino superior, bem como os currículos dos cursos que são elaborados no bojo da política educacional para os cursos de graduação e refletem na formação recebida. Tais concepções vêm sendo debatidas ao considerar a produção do conhecimento teórico e a prática profissional. Assim, a formação no ensino superior passa a exigir do egresso mais produtividade, flexibilidade para adaptação as novas formas de trabalho e competências e habilidades para lidar com a inovação tecnológica.

\section{A FORMAÇÃO EM HOTELARIA}

O ensino superior é responsável pela formação profissional que é regido pelos currículos dos cursos expressos nos Projetos Pedagógicos de Curso (PPC's). Von Linsingen (2006) afirma que interesses e pressões sociais diversos reclamam por renovações pedagógicas e curriculares para o atendimento de novas demandas profissionais exigidas por essas novas construções sociais. As instituições educacionais são instadas a mudarem o discurso tradicional de defesa de uma formação exclusivamente científica, para o de uma formação com ingredientes adicionais de responsabilidade, criatividade, competências diversas, flexibilidade, cooperatividade, negociação, aspectos humanísticos.

No paradigma do ensino superior, implantado a partir da Lei de Diretrizes e Bases - Lei n 9394 de 20 de dezembro de 1996, do primeiro Plano Nacional de Educação através da Lei no 10.172 de 9 de janeiro de 2001 que estabeleceu as Diretrizes Curriculares Nacionais (DCN’s) e do Parecer do Conselho Nacional de Educação /Câmara de Educação Superior 583/2001, pressupõe a formação especialmente pautada em competências e habilidades demandadas pelo egresso para o mercado de trabalho e que devem ser expressas nos currículos dos cursos de graduação (Brasil, 1996; 2001). Esses currículos são constituídos seguindo as DCN’s que estabelecem as orientações para a elaboração dos projetos pedagógicos de curso das Instituições de Ensino Superior (IES). Nesse entendimento Silva e Ramos (2006) destacam que o desenvolvimento se centra no enfoque crítico-reflexivo, que se baseia na reflexão, na tomada de decisão ou no confronto de ideias e concepções para resolver problemas. Ou seja, a formação deve possibilitar que o discente adquira competências específicas e transversais conectando teoria e prática. 
Ao analisar o ensino superior em turismo, Melo e Devile (2015) afirmam que em Portugal o Ensino Superior, assim como todos os níveis de ensino, passa por um período de reestruturação, que vai desde a reorganização da rede de ensino superior até a reflexão sobre a metodologia utilizada no processo de ensino-aprendizagem. Nos últimos anos têm vindo a ser propostos e apresentados modelos de ensino prático reflexivo, onde se valoriza a prática alicerçada no conhecimento científico, permitindo espaços onde os estudantes possam observar, analisar, atuar e refletir, através de um triplo movimento - conhecimento na ação, reflexão na ação e reflexão sobre a ação.

Em hotelaria, Correia, Salgado e Costa (2017) contextualizam que como área de conhecimento científico, se enquadra como uma das principais áreas do Turismo. Por sua vez, em termos setoriais, também consideram a hotelaria como uma atividade econômica fundamental do turismo, sobretudo por prestar serviços de alojamento, de restauração, entre outros diversos, que são essenciais à satisfação de necessidades de turistas. Esta reflexão epistemológica sobre o objeto científico da Hotelaria é necessária para permitir compreender a sua natureza e a inclusão no sistema educativo e científico de Portugal, tendo em vista a importância do setor no país.

No que se refere a importância da formação no contexto do trabalho, Neves, Magalhães e Lourenço (2007 como citado em Correia, Salgado \& Costa, 2017) explicam que apesar das IES se preocuparem em acompanhar as tendências, das dinâmicas do setor do turismo, não se pode concluir que existam diagnósticos de necessidades de formação consolidados pelas entidades e instituições de ensino e de formação, capazes de proporcionar respostas eficazes às necessidades do mercado de emprego.

No Brasil, em 2018 os dados da Sinopse Estatística do ensino Superior/Instituto Nacional de Estudos e Pesquisas Educacionais Anísio Teixeira - INEP/Ministério da Educação - MEC (2018) registraram 46 cursos de hotelaria no Brasil sendo 14 em IES públicas federais e 3 estaduais, e 29 em IES privadas, que podem ser cursos tecnólogos ou bacharelados.

As Instituições de Ensino Superior (IES) elaboram o Projeto Pedagógico de cada curso tendo em vista as especificidades da respectiva área de atuação expressa nos parâmetros para a ação educativa. Nesse documento constam: os conhecimentos e saberes considerados necessários à formação das competências estabelecidas a partir do perfil do egresso; estrutura e conteúdo curricular; ementário; bibliografias básica e complementar; estratégias de ensino; docentes; recursos materiais; serviços administrativos; serviços de laboratórios; e infraestrutura de apoio ao pleno funcionamento do curso. 
É importante destacar que a formação no ensino superior e o perfil do egresso em áreas como ciências sociais e aplicadas, levam ao desenvolvimento de conhecimentos, competências e habilidades muito similares, como planejamento e gestão, tomada de decisão, liderança, criatividade e inovação, empreendedorismo, ocasionando o acirramento no mercado de trabalho.

Em estudo sobre o perfil profissional e o mercado de trabalho, Gondim (2002) constatou que ao final do curso alguns egressos não conseguem delimitar sua identidade profissional, tendo em vista a ausência de clareza das habilidades e competências adquiridas e a escassa diferenciação da demanda de cada profissão no mercado de trabalho. Dito de outro modo, o estudante, de um lado, acredita que o mercado confunde os papéis profissionais, porque desconhece suas especificidades, tais como, as atividades de um psicólogo, de um administrador de empresas, de um sociólogo e de um assistente social e de outro, o próprio estudante, ao ser indagado acerca de seu perfil profissional tem dificuldade em explicitá-lo com clareza. Quando consegue fazê-lo e confronta com os perfis de estudantes de áreas afins, percebe muitas semelhanças entre eles e uma pergunta parece ficar sem resposta: afinal, se é possível exercer atividades semelhantes às de um colega com outra formação, o que define o perfil e a identidade profissional (o sujeito sociológico).

Nesse aspecto, Araújo e Ramos (2014) em estudo sobre empregabilidade do profissional em turismo na hotelaria no Brasil e em Portugal, evidenciaram que existe uma similaridade de habilidades e competências entre o conhecimento teórico e prático nos cursos de formação em Turismo e Hotelaria nas localidades pesquisadas.

\section{PROCEDIMENTOS METODOLÓGICOS}

O presente trabalho foi realizado com egressos do curso de bacharelado em hotelaria da Universidade Federal da Paraíba (UFPB) como resultado da segunda etapa do projeto de pesquisa Formação profissional em hotelaria: diagnóstico, avaliação e tendências, PIBICUFPB-CNPQ 2018-2019 e continuidade da pesquisa de Menezes e Cavalcanti (2020). O Curso de Bacharelado em Hotelaria da UFPB concluiu a primeira turma em 2010.1, e até 2018 havia 192 egressos do referido curso (Sistema integrado de gestão de atividades acadêmicas SIGAA/UFPB, 2018).

A primeira etapa do projeto foi realizada com os egressos do curso através de um questionário composto por questões sobre a graduação de bacharelado em Hotelaria e avaliação do ensino recebido, finalizando 40 respondentes dos 192 contatados (Menezes \& Cavalcanti, 2020). A segunda etapa da pesquisa, foi realizada com egressos que atualmente trabalham na 
hotelaria, tal requisito se justifica considerando que os que encontram-se no mercado de trabalho possibilitam fornecer informações úteis sobre o tema.

Dos 40 egressos participantes da primeira etapa, $45 \%(\mathrm{~N}=18)$ encontram-se trabalhando na hotelaria e, desse modo, foram selecionados para participarem da pesquisa. Para tanto, realizou-se uma pesquisa descritiva de abordagem qualitativa. A pesquisa qualitativa, segundo Ollaik e Ziller (2012), busca descrever e compreender um fenômeno e a concepção de validade assume formas distintas, pois a discussão sobre escalas de medição não se aplica a métodos qualitativos, sendo necessária a compreensão da validade em outra perspectiva. Para a coleta de dados considerando a temática ensino superior e formação profissional a utilizou-se a técnica de entrevista de Grupo Focal.

Nas investigações na área da educação, as entrevistas de Grupo Focal oferecem a
oportunidade de armazenar dados qualitativos relativos à percepções e opiniões de
indivíduos selecionados. Se aplicadas adequadamente o investigador poderá captar
informações preciosas sobre os pensamentos e sentimentos dos participantes (Gomes,
2008, p. 8).

Para o Grupo Focal foram convidados egressos de períodos diferentes de ingresso e em relação à moderação, foi realizada por um membro do projeto sem vínculo anterior com os participantes, uma vez que "recomenda-se não juntar no mesmo grupo pessoas que se conhecem muito, ou que conheçam o moderador" (Gatti, 2012, p. 21). Minayo (2000 como citado em Mendonça \& Gomes, 2016) explica que nos critérios para a formação do Grupo Focal, pode-se levar em consideração o ambiente de trabalho dos participantes, o exercício profissional, a partilha das mesmas características em nível de escolaridade, as condições sociais ou ainda, se todos foram funcionários de um único setor, deve-se ter em conta que a formação do grupo permita um ambiente favorável à discussão e propicie aos participantes manifestar suas percepções e pontos de vista.

Gatti (2012) explica que o trabalho com grupos focais permite compreender processos de construção da realidade por determinados grupos sociais. Nesse entendimento, permite compreender a relação entre formação do profissional e prática de mercado trabalho e as tendências para a formação profissional em hotelaria de forma mais aprofundada.

Elaborou-se um roteiro que foi seguido na execução do Grupo Focal, de modo que o mesmo serviu de orientação sobre os temas a serem abordados para obtenção dos dados. Como o Grupo Focal tem por objetivo aprofundar as questões da pesquisa, 9 egressos foram convidados e confirmados para a sessão, contudo 7 egressos participaram. Registra-se ainda 
que conforme Gatti (2012) o Grupo Focal deve ter entre seis e doze participantes e, em geral o ideal é não trabalhar com mais de 10 participantes.

A sessão de Grupo Focal foi filmada e gravada, transcritas e posteriormente submetida a técnica de análise de conteúdo. Bardin (2009) explica que a análise de conteúdo é uma técnica que através de procedimentos objetivos e sistemáticos descrevem o conteúdo das mensagens de comunicações extremamente variadas. O recorte do material foi realizado estabelecendo as unidades de registro (palavras e frases) comparáveis e com o mesmo conteúdo que foram agrupadas em categorias e subcategorias. As unidades de registro de cada subcategoria determina a sua importância.

\section{ANÁLISE DOS RESULTADOS}

Foram definidas categorias de análise de modo que possibilitasse a organização e análise das informações obtidas. "A análise deve extrair tudo que for relevante e associado ao tema ou à categoria. As categorias podem ser geradas a partir das informações obtidas" (Gomes, 2005, p. 15). Desse modo, foram formadas três categorias de análise e oito subcategorias apresentadas no Quadro 1. As referidas categorias visam a atender aos objetivos do estudo: analisar a relação entre a formação do profissional e prática de mercado de trabalho na perspectiva dos egressos do curso de hotelaria.

Quadro 1 - Síntese das categorias de análise

\begin{tabular}{|c|c|c|}
\hline $\begin{array}{l}\text { Categoria de } \\
\text { Análise }\end{array}$ & Subcategoria de Análise & Eixo norteador \\
\hline \multirow{3}{*}{$\begin{array}{l}\text { Ensino Superior em } \\
\text { hotelaria }\end{array}$} & Contexto da educação em hotelaria & $\begin{array}{l}\text { Considerações sobre o ensino em hotelaria no } \\
\text { País. }\end{array}$ \\
\hline & $\begin{array}{l}\text { Organização do ensino superior em } \\
\text { hotelaria }\end{array}$ & $\begin{array}{l}\text { Questões sobre objetivo do curso, perfil } \\
\text { profissional, conhecimentos, currículo e } \\
\text { organização das disciplinas. }\end{array}$ \\
\hline & $\begin{array}{l}\text { Oferta dos cursos de hotelaria no } \\
\text { Brasil }\end{array}$ & $\begin{array}{l}\text { Comentários relacionados aos cursos de } \\
\text { bacharelado e tecnólogo. }\end{array}$ \\
\hline \multirow{3}{*}{$\begin{array}{c}\text { Formação } \\
\text { profissional em } \\
\text { hotelaria }\end{array}$} & $\begin{array}{l}\text { Como avaliam o curso e a formação } \\
\text { recebida }\end{array}$ & $\begin{array}{l}\text { Exposições e sentimentos sobre a formação } \\
\text { recebida ao longo do curso. }\end{array}$ \\
\hline & $\begin{array}{l}\text { Caminho para a formação do } \\
\text { profissional de hotelaria }\end{array}$ & $\begin{array}{l}\text { Comentários sobre como melhorar a } \\
\text { formação em hotelaria. }\end{array}$ \\
\hline & $\begin{array}{l}\begin{array}{l}\text { Propostas para a formação em } \\
\text { hotelaria }\end{array} \\
\end{array}$ & $\begin{array}{l}\text { Sugestões para melhoria da formação em } \\
\text { hotelaria. }\end{array}$ \\
\hline \multirow{2}{*}{$\begin{array}{l}\text { Mercado de } \\
\text { trabalho e prática } \\
\text { profissional }\end{array}$} & $\begin{array}{l}\text { Relação entre a formação profissional } \\
\text { e a prática profissional na área de } \\
\text { hotelaria }\end{array}$ & $\begin{array}{l}\text { Relatos sobre o ensino superior em hotelaria, } \\
\text { a prática profissional e a teoria. }\end{array}$ \\
\hline & $\begin{array}{l}\text { Identidade do bacharel em Hotelaria } \\
\text { como profissional }\end{array}$ & $\begin{array}{l}\text { Comentários sobre o significado da profissão } \\
\text { e seus sentimentos. }\end{array}$ \\
\hline
\end{tabular}

Fonte: Elaborado pelas autoras, 2020. 
A seguir são apresentadas as análises a partir das falas dos egressos, para que os sujeitos da pesquisa não fossem identificados foram definidas letras aleatórias para nomear cada egresso.

\subsection{Categoria de análise: ensino superior em hotelaria}

A categoria de análise Ensino Superior em hotelaria proporcionou através da análise três subcategorias.

Quadro 2 - Categoria de análise: ensino superior em hotelaria

\begin{tabular}{|c|c|}
\hline \multicolumn{2}{|r|}{ Categoria de análise: Ensino Superior em hotelaria } \\
\hline Subcategorias & Exemplos de Verbalizações \\
\hline $\begin{array}{c}\text { Contexto da } \\
\text { educação em } \\
\text { hotelaria }\end{array}$ & $\begin{array}{l}\text { "[...] eu percebi que a nossa formação, ela assim, trouxe um embasamento, gerencial muito } \\
\text { forte, tanto é que boa parte dos alunos, a gente observa que seguiram, um caminho mais } \\
\text { gerencial, até os alunos que seguiram para parte acadêmica, procuraram fazer as pós- } \\
\text { graduações, mais ligadas a questões, mais gerencial mesmo." (J.L.) } \\
\text { "Na minha formação, a gente debatendo na sala de aula, eu tive um choque de realidade } \\
\text { muito grande quando eu sai do curso de hotelaria e fui me inseri no mercado de trabalho, } \\
\text { hotelaria, nenhum hoteleiro, então tudo era muito distante do que a gente estudava, era tudo } \\
\text { muito distante da realidade: na hotelaria eles fazem assim, na governança as coisas } \\
\text { acontecem dessa forma, então a educação, o processo informativo, estava muito distante do } \\
\text { que a gente observa na prática ... que o objetivo atual do curso de hotelaria, com esse novo } \\
\text { PPC, é diminuir um pouco mais essa distância, entre a academia e o mercado de trabalho, } \\
\text { talvez essa mudança de PPC." (L.) } \\
\text { "Senti mesmo o choque muito grande, por que a gente precisa, como vocês estão falando, } \\
\text { do operacional, e precisamos da teoria, hoje a nossa universidade, está muito distante da } \\
\text { outras universidades que possuem curso de hotelaria, vamos se basear na referência, lá eles } \\
\text { tem o hotel escola , lá eles aprendem no operacional, eles tem a teoria , na prática, tanto, } \\
\text { que os grande, conheço alguns, nomes da hotelaria são de lá, e vieram, fizeram } \\
\text { especialização lá, é uma universidade de referência, então nesse contexto da hotelaria no } \\
\text { mercado hoje, na parte de educação, aqui sofre ainda, e vamos sofrer."(M.) } \\
\text { "Eu acredito que, o caminho é longo, e ardo, e se a gente abraça a causa, se a gente, quem } \\
\text { já passou, pela academia assim, se abraça a causa e faz, levanta a bandeira, eu acredito que } \\
\text { um vai puxando o outro, e é isso que vai acontecendo com uma geração, com outra geração } \\
\text { e a gente tá vendo o pessoal engajado aqui." (W.) }\end{array}$ \\
\hline $\begin{array}{c}\text { Organização } \\
\text { do ensino } \\
\text { superior em } \\
\text { hotelaria }\end{array}$ & $\begin{array}{l}\text { "É, a gente tem ciência da mudança do PPC recentemente, mas ainda deixa a desejar, tem } \\
\text { algumas coisas, por exemplo, como as meninas que estão vivenciando isso na prática da } \\
\text { hotelaria hospitalar, o nosso novo PPC tem uma única disciplina de hotelaria hospitalar que } \\
\text { é insuficiente pra apresentar de fato o que é uma hotelaria hospitalar pro aluno." (L.) } \\
\text { "A gente precisa se situar no mercado, pra que a gente não entregue um aluno tão verde pra } \\
\text { hotelaria. Por que muitas vezes o nosso curso é tachado como "qualquer um pode e lá e } \\
\text { fazer". O aluno ele tem que sair daqui com uma característica diferente. Qual o seu } \\
\text { diferencial no mercado de trabalho?" (L.) } \\
\text { "É assim, a questão, eu acho que pra vocês, que trabalham na parte da educação, artigos, } \\
\text { pesquisa, o PIBIC, que ... tá fazendo. Isso, esse grupo focal, isso é o que vai fazer o curso se } \\
\text { aproximar as pesquisas. Gente, a gente tem poucos artigos, poucas coisas sobre a hotelaria. } \\
\text { Eu digo por que eu pesquiso. Muito pouca coisa, sobre como é que tá a hotelaria hoje, a } \\
\text { gente tem só gerente falando de hotel, um querendo vender a sua sardinha, mas pouca coisa } \\
\text { pra área de conhecimento da gente, do que realmente se passa em um hotel. Estudos de caso? } \\
\text { Poucos estudos de caso. Poucos livros com estudo de caso." (M.) }\end{array}$ \\
\hline
\end{tabular}




\begin{tabular}{|c|c|}
\hline $\begin{array}{c}\text { Oferta dos } \\
\text { cursos de } \\
\text { hotelaria no } \\
\text { Brasil }\end{array}$ & $\begin{array}{l}\text { "O tecnólogo, é já pronto pra atuar no mercado. Já nós que somos bacharéis, estamos bem, } \\
\text { assim, preocupado nos trabalhos acadêmicos, da vida acadêmica, dos artigos, nós nos } \\
\text { pegamos mais nesse movimento da educação. E o tecnólogo ele está mais pronto por ser um } \\
\text { curso em pequeno espaço de tempo, mais pronto pra entrar no mercado de trabalho. Ele vem } \\
\text { com o curso todo dividido. Ele vê a parte de gastronomia, ele vê a parte de reserva, ele } \\
\text { adentra mais rápido no mercado de trabalho, ele capta ele melhor. Assim as pessoas me } \\
\text { falaram." (G.) } \\
\text { "Eu discordo um pouquinho, eu acredito, discordo em partes. Eu acredito que como J. falou, } \\
\text { o curso de tecnólogo ele volta mais pra atividades operacionais, de um nível, mais baixo } \\
\text { digamos. O aluno ele é formado pra recepção, o aluno ele é formado pra garçom, pra } \\
\text { camareira, pra níveis mais baixos. E o bacharelado, tem essa tendência, ao menos, ser mais } \\
\text { gerencial. A gente coloca como chefe de recepção, como M., como gerente de recepção, } \\
\text { gerente de A\&B, então, eu acredito muito nessa divisão. Nesse sentido." (L.) } \\
\text { "Pois é, eu tenho observado, que algumas outras universidades; Quando a gente começou } \\
\text { a fazer, pouquíssimas universidades, tinham curso de hotelaria. Eu tenho observado que } \\
\text { outras universidades têm surgido com o curso de hotelaria. Mas, a gente observa que, pelo } \\
\text { menos aqui, no nordeste, a gente não vê, faculdades particulares, oferecendo o curso de } \\
\text { hotelaria. Isso quer dizer alguma coisa, por que será que as universidades particulares não } \\
\text { oferecem o curso de hotelaria?" (J.) }\end{array}$ \\
\hline
\end{tabular}
Fonte: Elaborado pelas autoras, 2020.

No que concerne ao contexto da educação em hotelaria, os relatos permitiram determinar uma distância entre a formação e o mercado de trabalho, sobretudo no que se refere aos conhecimentos operacionais na hotelaria. Sobre esse tema, apesar do predomínio do discurso a favor da unidade entre a teoria e a prática, Pimenta (2009) analisa que na formação profissional, o que se tem visto nas produções científicas do campo educacional é a falta de uma articulação entre elas.

A subcategoria organização do ensino superior em hotelaria que está associada as questões sobre objetivo do curso, perfil profissional, conhecimentos, currículo e organização das disciplinas, que constam no Projeto Pedagógico de Curso (PPC) e são elaborados seguindo as orientações e normas das Diretrizes Curriculares Nacionais (DCN’s) para os cursos de graduação estabelecido pelo Ministério da Educação (MEC). Sobre essa organização, as argumentações remetem para a preocupação da organização do curso e, no caso, da estrutura curricular relacionada com o mercado, expressadas através de problemáticas relacionadas às práticas de mercado, seja por meio de conteúdos como o exemplo da hotelaria hospitalar, seja por pesquisas, para aproximar com o mercado de trabalho. É essencial reforçar que conforme explica Goergen (2000), o ensino superior tem focado no atendimento a demandas da 
produtividade e do crescimento econômico, da prestação de serviços, do domínio da ciência e da tecnologia, claramente fruto de uma orientação de ordem capitalista. E, nesse aspecto, encontram-se as bases para a organização dos cursos de graduação no país. Registra-se que um novo PPC para o curso de hotelaria foi aprovado em junho de 2018 e está sendo implantado (Resolução ConsEPE ${ }^{1} n^{\circ}$ 12/2018), sendo que algumas disciplinas que antes abordavam os conteúdos relacionados a prática profissional passaram a ser oferecidas em disciplinas inseridas nos conteúdos básicos profissionais com nomes e ementas mais adequadas às necessidades da formação dos discentes como: Reservas e recepção, Governança e lavanderia, Hotelaria hospitalar, Introdução a Alimentos em Hotelaria, Tecnologia Culinária, Gestão em A\&B, Bebidas e Enologia, Gestão de Vendas em Hotelaria, entre outras. A carga-horária do estágio curricular também foi ampliada para 300 horas.

Em relação à oferta dos cursos de hotelaria os egressos realizaram comparação entre os cursos de bacharelado e tecnólogos e avaliam que na região nordeste os cursos em instituições particulares são menos ofertados. Ao traçarem o panorama dos cursos de bacharelado em hotelaria, Menezes e Cavalcanti (2020) constataram que a maioria encontra-se em universidades federais na região nordeste. Os autores registram também que entre 2005 e 2017 houve diminuição do número de cursos de bacharelado em hotelaria no país e, em relação aos cursos superiores tecnólogos em hotelaria, observa-se um aumento na oferta e ponderam que tal fato pode ser em decorrência dos cursos tecnólogos serem cursos superiores com menor tempo de duração e ter como proposta uma maior prática ao longo da formação.

\subsection{Categoria de análise: formação profissional em hotelaria}

A referida categoria foi dividida em três subcategorias que possibilitou compreender a formação nas perspectiva dos participantes da pesquisa.

Quadro 3 - Categoria de análise: formação profissional em hotelaria

\begin{tabular}{|l|l|}
\hline Cabcategorias & \multicolumn{1}{c|}{ Exemplos de Verbalizações } \\
\hline "Eu vou classificar. Eu acho que a nota, é nota C. Para o tempo que me formei. [...]Os \\
professores foram ótimos. Os professores me deram suporte até quando eu estava lá. Mas, \\
a questão do que foi proposto, como foi feito o organograma da disciplina, não ajudou a \\
eu sair e entrar no mercado de trabalho. O que me ajudou foi, depois que eu sai. As \\
professoras, A., a professora P., a professora R., a professora J., os professores que me \\
acompanharam, me deram suporte e me ensinaram aonde pesquisar, aonde ir, o que fazer. \\
$\begin{array}{l}\text { E foi assim que eu fui crescendo mesmo, buscando mesmo, pra poder hoje está no mercado } \\
\text { de trabalho. Inserida no mercado de trabalho. Não desisti. Por que a pessoa as vezes, } \\
\text { quando tem esse choque de realidade a pessoa desiste. Muitas pessoas desistiram. Eu não }\end{array}$
\end{tabular}

${ }^{1}$ Conselho de Ensino, Pesquisa e Extensão. 


\begin{tabular}{|c|c|}
\hline $\begin{array}{c}\text { Como avaliam o } \\
\text { curso e a } \\
\text { formação } \\
\text { recebida }\end{array}$ & 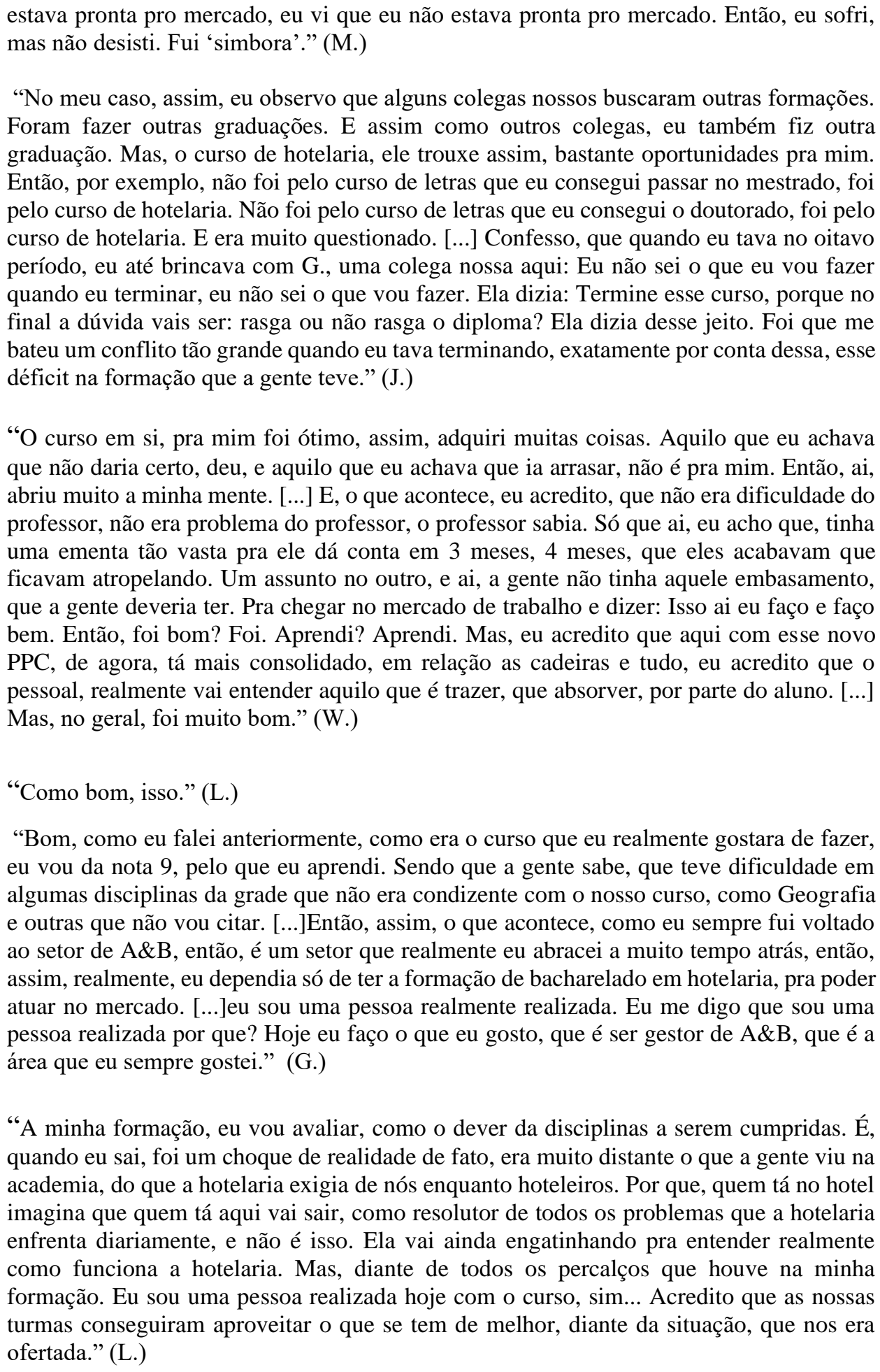 \\
\hline $\begin{array}{l}\text { Caminho para a } \\
\text { formação do }\end{array}$ & $\begin{array}{l}\text { "Eu acho que a hotelaria hoje tá em crise. Não sei se vocês tem esse mesmo pensamento... } \\
\text { a hotelaria não é a mesma coisa, então assim, eu acho que o curso de hotelaria, ele tem que } \\
\text { trabalhar em cima do mercado que existe hoje, com as novas tendências do mercado que } \\
\text { existe hoje, pra poder subir. [...]Como a hotelaria hoje, ela está mudando, porque a gente } \\
\text { vê esses contextos, com muita questão operacional, mas a gente também tem que ver o } \\
\text { contexto global, pelo que a hotelaria está passando." (M.) } \\
\text { "E a tecnologia em sistemas, que hoje em dia só cresce. No hotel mesmo que eu trabalho. } \\
\text { A gente trabalha com canais, que chegam e facilitam as vendas. Hoje em dia a gente } \\
\text { praticamente... antigamente, eu lembro que no primeiro hotel que eu trabalhei existia as }\end{array}$ \\
\hline
\end{tabular}




\begin{tabular}{|c|c|}
\hline $\begin{array}{l}\text { profissional de } \\
\text { hotelaria }\end{array}$ & 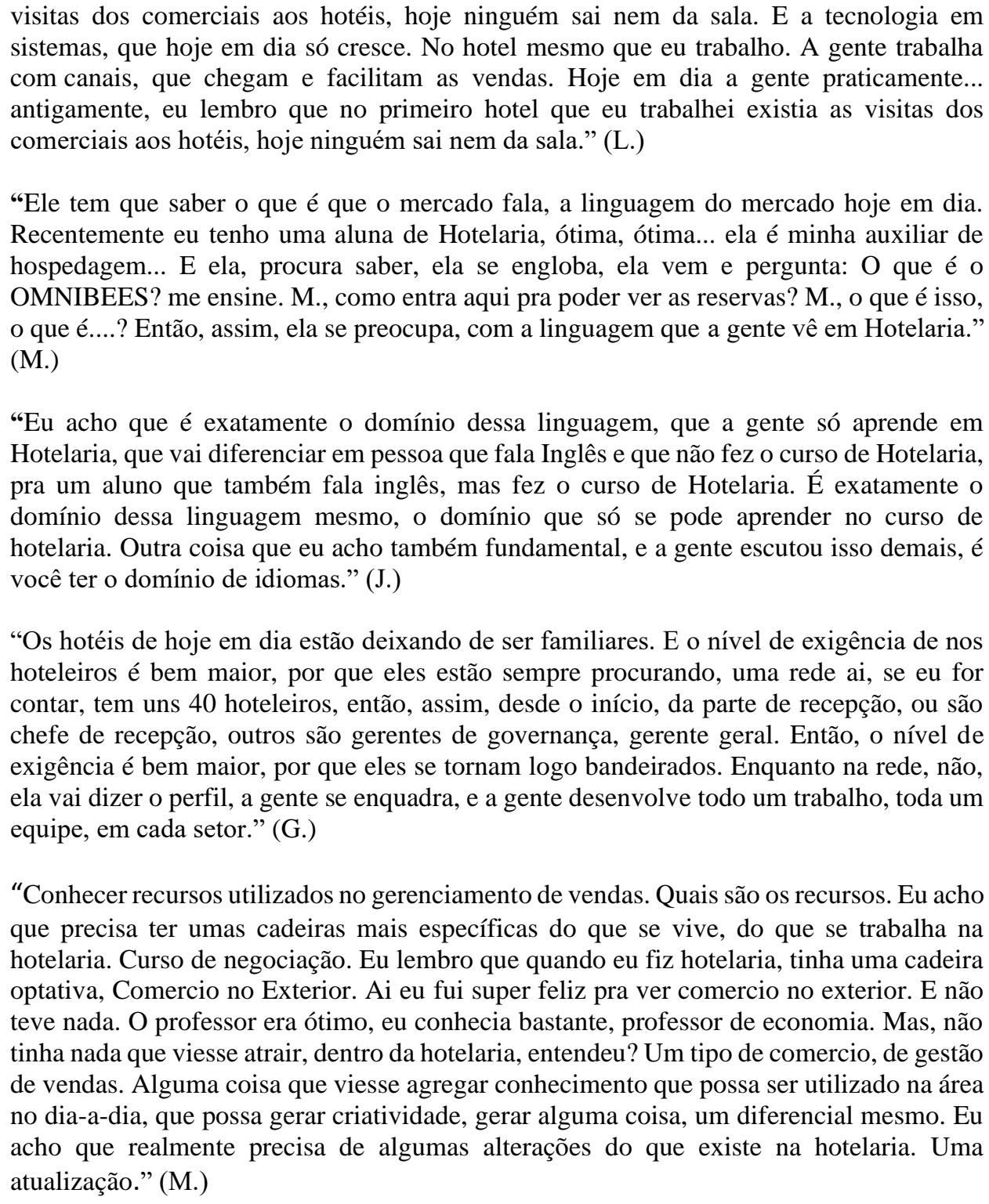 \\
\hline $\begin{array}{c}\text { Propostas para a } \\
\text { formação em } \\
\text { hotelaria }\end{array}$ & $\begin{array}{l}\text { "Eu acredito, que é importante, que o aluno saia daqui com essa visão interdisciplinar. É } \\
\text { lógico que dentro da hotelaria, existe áreas que a gente vai ter mais afinidades. } \\
\text { Obviamente, um hotel tem todas essas áreas. Mas, na nossa época, eu via esse curso, muito } \\
\text { mais tendencioso pra A\&B, do que pra o novo PPC de agora. Porque na minha época, eu } \\
\text { tinha impressão que eu estava fazendo cozinha, não era nem gastronomia, era cozinha de } \\
\text { fato. [...]Que a gente precisa entender, que a engrenagem funciona, com a parceria de cada } \\
\text { um dos setores, e temos que entender o papel e o objetivo de cada um deles. Eu vejo mais } \\
\text { por esse viés, da interdisciplinaridade, de entender o hotel como um mecanismo composto, } \\
\text { complexo, onde cada setor precisa da sua atitude pra que o hotel funcione da melhor forma } \\
\text { possível." (L.) } \\
\text { "Então, a polivalência, eu acho realmente, hoje, no Brasil que a gente está, a polivalência, } \\
\text { ela é essencial na hotelaria. Eu tenho que ser polivalente, não só ser, eu não posso ser só } \\
\text { recepcionista, tem que ser recepcionista, tem que ser mensageiro, tem que limpar, ser o } \\
\text { auxiliar de serviços gerais, eu tenho que ser tudo. Eu tenho que saber da governança. Eu } \\
\text { tenho que ter essa polivalência, e como eles falaram, também ter essa interdisciplinaridade, } \\
\text { conhecer, o saber. Eu acho, assim, que são competências essenciais, hoje, de qualquer } \\
\text { profissional, seja lá de outra área, mas de hoteleiro, o que o mercado procura. Eu acho que } \\
\text { as pessoas, que têm se destacado, principalmente na parte gerencial, parte da hotelaria } \\
\text { mesmo, é isso. Esses são os requisitos. Que os gestores maiores procuram, que a empresa } \\
\text { procura, de cada um de nós." (M) }\end{array}$ \\
\hline
\end{tabular}


"Então, se vai fazer a hotelaria, se vai concluir hotelaria, a hotelaria tem opções enormes. Vai fazer? Faz aquilo que você sabe que vai levar pra frente. A competência, a proatividade, só concordando com o que você, M., colocou, concordo com tudo, em todos os pontos que você falou, e a pró-atividade também. Porque, se pegar um caso que nem o de L., de "não faço não.", mas o hotel, hospital, tá ali girando. Então, porque ele não vai fazer, eu ao invés de fazer, não vou fazer? Então, temos que também, ser proativos nessas situações. Ela não quer fazer? Tá bem, eu faço. Vou lá e mando. É como L. disse, é uma engrenagem, se parar..." (W.)

"Algo mais voltado a realidade que a gente vive na hotelaria, e que acompanhasse as inovações, do mercado também. Como você (M.) falou, sistema. É algo 'novo', mas que vem crescendo, e é essencial. Como você (L.) falou, o aluno está ali no celular, já vê a diária, é uma ferramenta. É bom? É ótimo, mas também tem o outro lado. Então, creio que uma grade curricular deve envolver muito isso, acompanhar as inovações, e estar sempre se adequando a essas inovações e novidades, como o mercado de trabalho também. O que ele exige, a nossa realidade de trabalho. Que é o que o profissional vai fazer no futuro. Ele vai pra realidade, ele estuda, mas vai pra realidade, e tem que estar acompanhando, tem que tá junto.” (A.)

"Olhando para o mercado, como eu acabei de falar, eu acho que é um principal viés, como M. colocou, a gente tem que entender, o que o mercado tá precisando pra gente poder ofertar. Não adianta de nada a gente tá falando aqui, e por exemplo, vou dar o exemplo da disciplina de Governança e Lavanderia. Antigamente a gente tinha um estilo de limpeza do quarto, que a gente utilizava muita água, muito produto de limpeza, pano, uma determinada vassoura, e hoje em dia existe o método que a gente usa o mínimo possível de recurso, o mínimo possível de material, com objetivo e fim, que é a redução de custos e a qualidade de prestação de serviços. Então, isso foi, pra atender uma demanda da hotelaria. Então, a gente tem que entender, qual a demanda que a hotelaria tá tendo, que os hotéis estão precisando. O que a gente pode se capacitar." (L.)

Fonte: Elaborado pelas autoras, 2020.

A partir da análise, constatou-se que os egressos avaliaram como bom o curso e a formação recebida, entretanto, apontaram alguns problemas relacionados ao currículo proposto no que diz respeito ao conteúdo ou em relação a quantidade de conteúdo para determinada disciplina.

Considerando que os currículos são dinâmicos e, que de acordo com a legislação, os cursos devem ser reformulados para se adequarem à realidade da sociedade, foi questionado sobre como deve ser a formação profissional em hotelaria: A partir das declarações evidenciase, sobretudo, questões relacionadas ao mercado, as novas tecnologias e aspectos do cotidiano de trabalho reforçando a aproximação com o mercado de trabalho.

Ao longo do Grupo Focal os egressos apontaram algumas propostas para a formação em hotelaria enfatizando os temas de inovação, tecnologia e mercado e consideram que o profissional deve ser polivalente, proativo e ter visão holística. É fundamental registrar que as DCN’S e o PPC do curso em suas propostas já elencam tais requisitos para a formação desse profissional, de modo que deve ser realizado uma avaliação para verificar quais as razões e circunstâncias tem produzido lacunas nesses aspectos ao longo do curso. 


\subsection{Categoria de análise: mercado de trabalho e prática profissional}

A última categoria foi dividida em duas subcategorias, com relatos sobre o ensino em hotelaria, a prática profissional e sentimentos sobre a profissão e a identidade dos egressos.

Quadro 4 - Categoria de análise: mercado de trabalho e prática profissional

\begin{tabular}{|c|c|}
\hline \multicolumn{2}{|r|}{ Categoria de análise: Mercado de trabalho e prática profissional } \\
\hline Subcategorias & Exemplos de Verbalizações \\
\hline $\begin{array}{l}\text { Relação entre a } \\
\text { formação } \\
\text { profissional e a } \\
\text { prática } \\
\text { profissional na } \\
\text { área de } \\
\text { hotelaria }\end{array}$ & $\begin{array}{l}\text { "É o que eu falo, isso a gente não viu, eu não sei se vocês viram, mas a linguagem no } \\
\text { contexto hoteleiro mesmo, o que se fala dentro dos hotéis, era sofrido, eu tive que estudar, } \\
\text { procurar saber. Eu sei visse (teclando). Aprendi pesquisando. A questão do Revpar, gente, } \\
\text { é um mundo que eu, realmente, eu conhecia a questão do Revpar, conhecia o que significava } \\
\text { o Revenue Management, por que eu comecei na área de recepção e pesquisei. Mas, quando } \\
\text { ele fez o curso e ele trouxe isso pra nossa realidade eu disse: Caramba, eu tenho que aprender } \\
\text { sobre isso bem direitinho. Por que é um mundo, é um mundo dentro do setor de reservas, e } \\
\text { ai que vai a questão que eu falei, a globalização, da crise, ai a gente vai ver realmente, nosso } \\
\text { hotel ta dando lucro?" (M.) } \\
\text { "Como eu vejo, foi o que eu falei, se a gente tivesse um hotel escola, seria muito mais fácil } \\
\text { a gente ter a teoria e a prática juntas." (G.) } \\
\text { "Outra coisa que a gente bate a dificuldade, entre a teoria e a prática. Quando eu sai pra } \\
\text { implantar a pousada, a gente teve uma disciplina de planejamento. O planejamento ajudou } \\
\text { bastante, na área do que fazer, de ver a questão da planta, e tá, peguei a arquiteta. Pra você } \\
\text { fazer um hotel, hoje alguém ter um hotel, tem que ter um hoteleiro do lado. Os donos de } \\
\text { hotéis não entendem isso, tem que ter hoteleiro do lado. Se você vir o Hotel X, é o hotel que } \\
\text { eu trabalho, mas a arquiteta não entende nada de hotelaria, nada." (M.) } \\
\text { "[...] isso demonstra que eles tão sabendo fazer a coisa, a hotelaria é muito do saber fazer. } \\
\text { A teoria, às vezes a gente sabe da teoria, mas quando vai colocar a mão na massa, se você } \\
\text { não souber, infelizmente você é colocado pro lado, entendeu? Então, eu acredito que a } \\
\text { esperança da competência e da habilidade, está no saber fazer, de colocar a mão na massa, } \\
\text { e de não ter preguiça de fazer." (J.) }\end{array}$ \\
\hline $\begin{array}{c}\text { Identidade do } \\
\text { bacharel em } \\
\text { Hotelaria como } \\
\text { profissional }\end{array}$ & $\begin{array}{l}\text { "Lá na minha cidade, o povo falava: Ah, que legal M., você vai trabalhar numa horta, fazer } \\
\text { uma plantação, fazenda." (M.) } \\
\text { "Por que até muitos dizem: Hotelaria não é profissão. Eu já ouvi várias pessoas me dizerem } \\
\text { isso. Você no final vai se formar hoteleira? Muita gente disse isso. Chegaram pra mim } \\
\text { dizendo isso. Tem noção? Então pra você vê o nível de conhecimento das pessoas, sobre o } \\
\text { curso, em relação a isso. Ai quando eu ficar velho eu não vou servir mais pra isso, pra } \\
\text { hotelaria. Você serve hoje por que você é bonitinha, você é nova, você é jovem. Veio muita } \\
\text { gente me dizer isso." (L.) } \\
\text { "O que é o curso, o que são as pessoas, o que são os gestores. O que são as pessoas que tão } \\
\text { crescendo. Agora está sendo mais visto. "Você se formou em que curso? Hotelaria". Existe } \\
\text { isso? ...” (M.) } \\
\text { "Na época que eu estagiei, eu estagiei em dois hotéis. O primeiro hotel não permitia eu usar } \\
\text { o computador, por que eu poderia quebrar ou danificar. Eu estagiei no setor de eventos, no } \\
\text { período que eu estive lá não teve nenhum evento no hotel. E eu passava o horário da tarde } \\
\text { estudando. Porque eu não podia pegar no computador e não tinha acesso ao sistema, então } \\
\text { eu fazia o que eles falavam.” (L.) }\end{array}$ \\
\hline
\end{tabular}




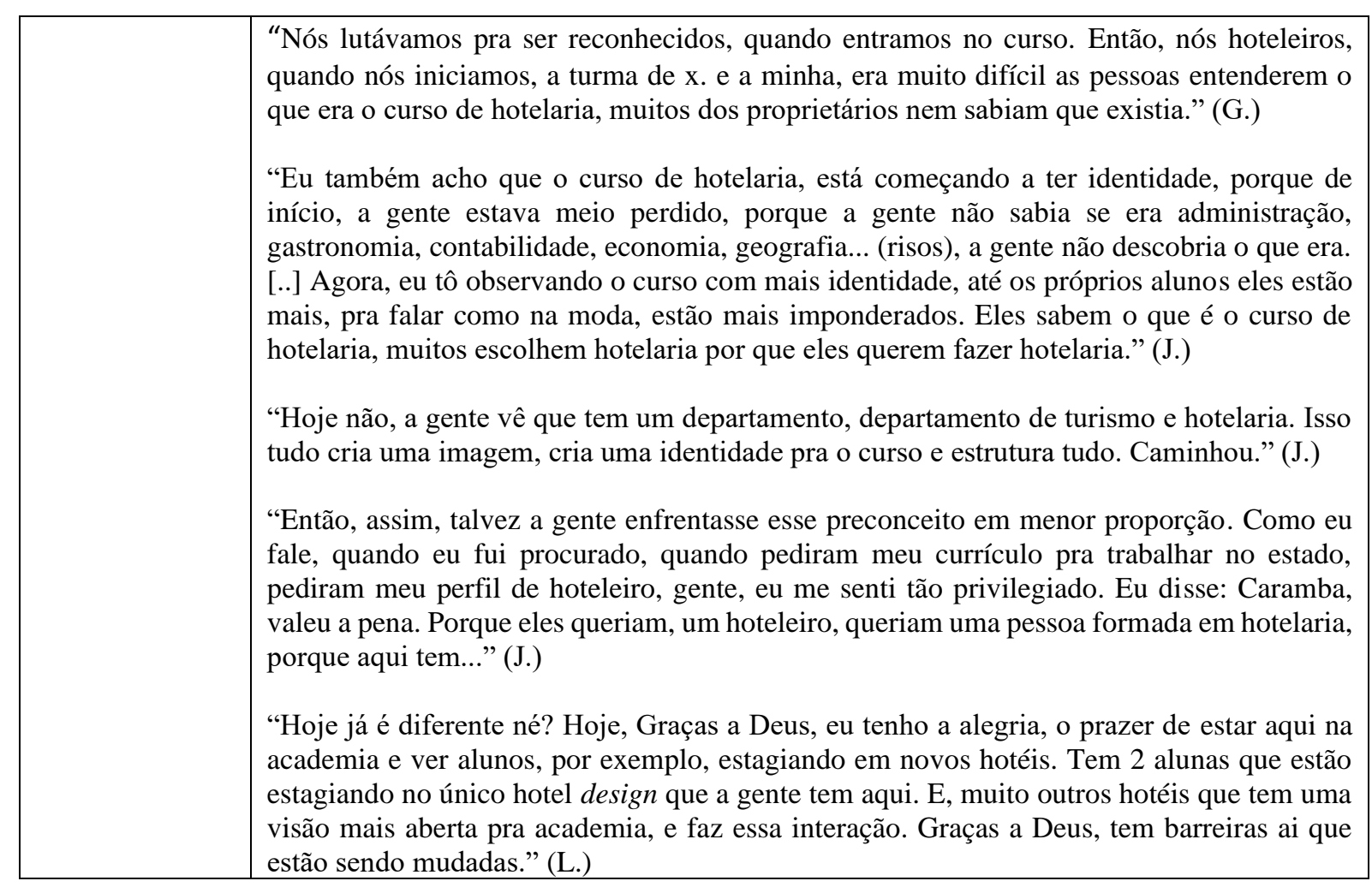

Fonte: Elaborado pelas autoras, 2020.

Buscando aprofundar o tema foi questionado sobre a relação entre a formação e a prática profissional e as falas complementaram os relatos anteriores, sobretudo em relação as lacunas relacionadas a aquisição conhecimentos práticos no decorrer do curso. Nesse sentido, Araújo e Ramos (2014) constataram que os cursos de Hotelaria e Turismo que formam os profissionais para o setor turístico, em termos de conteúdo, estão adequados às funções, sendo, no entanto, necessário o desenvolvimento de mais atividades práticas e mais aproximação à realidade laboral.

No bojo da problemática de formar o profissional para o mercado de trabalho os egressos direcionam também para a questão da valorização profissional e da carência de conhecimento sobre a função do hoteleiro, inclusive expressando ao longo dos registros que precisaram lutar para serem reconhecidos.

Pimenta (2009) afirma que uma identidade profissional se constrói, pois, a partir da significação social da profissão; da revisão constante dos significados sociais da profissão, da revisão das tradições. Por sua vez, Gondim (2002) ao analisar a identidade profissional tomou como referência do sujeito sociológico, cuja identidade é construída na interação do eu com a sociedade e cuja ênfase recai naquilo que as pessoas têm em comum enquanto grupo sociocultural (a identidade está naquilo que a pessoa compartilha com o grupo), pois está mais afinada com a perspectiva de entendimento de que a inserção no mercado depende 
significativamente da demarcação do que cada profissional tem em comum com outros profissionais de sua área e de diferente em relação àqueles que atuam em outras áreas.

Nesse caso, duas vertentes se apresentam, a primeira como já abordada as competências e habilidades e a delimitação da área de atuação de egressos de cursos superiores de determinadas áreas e, a segunda, o desconhecimento pelos empresários e pela sociedade do profissional de hotelaria, a condição social do Bacharel em Hotelaria.

\section{CONSIDERAÇÕES FINAIS}

Em virtude das transformações da sociedade o papel das Universidades sofreu alterações relevantes e, atualmente, a exigência no ensino superior é para que forme profissionais para atuarem no mercado de trabalho. No bojo dessa premissa, Ribeiro (2007) esclarece que existe a pressão para que outros conhecimentos ocupem o lugar daqueles que eram conservados do passado e, hoje são pragmaticamente inúteis para o exercício da profissão, de modo que, a universidade enfrenta, portanto, a tensão produzida pelo impasse entre atender às necessidades que ela detecta como um déficit da sociedade e as demandas sociais que the são endereçadas como capazes de fazer frente aos processos de reestruturação produtiva em curso.

Nesse sentido, os currículos dos cursos são elaborados visando a atender tais demandas, contudo, algumas lacunas surgem e merecem ser analisadas. O presente artigo evidencia a necessidade de reforçar na formação conhecimentos específicos para o cotidiano das atividades laborais. A pesquisa conseguiu atingir o objetivo de analisar a relação entre a formação do profissional e prática de mercado de trabalho e evidenciou que a prática é fundamental, entretanto, os egressos pontuaram que é uma lacuna que não tem sido preenchida na formação oferecida no curso de hotelaria da UFPB, sobretudo, em decorrência do curso não possuir laboratórios. Em relação às tendências para o profissional em hotelaria, de acordo com os egressos as mudanças têm ocorrido especialmente em virtude das tecnologias da informação e comunicação. A maioria dos entrevistados analisam que o curso de bacharelado em hotelaria ainda está se desenvolvendo e que a profissão está ganhando espaço no mercado de trabalho aos poucos e expuseram que não são todos que conseguem se fixar e ter a estabilidade desejada.

Registra-se que em relação aos conhecimentos, currículo e organização das disciplinas o Projeto Pedagógico de Curso aprovado em 2018 buscou corrigir alguns dos problemas elencados, entretanto, após a conclusão de turmas desse PPC deve-se realizar pesquisas para examinar se as demandas estão sendo atendidas.

Evidencia-se que é de extrema importância a construção da formação onde a vivência prática esteja conectada a teoria e atenta as tendências e inovações que estejam acontecendo no 
setor e no mundo. Estudos sobre o tema são fundamentais para um melhor entendimento sobre as questões relacionadas ao ensino superior e a formação profissional.

\section{REFERÊNCIAS}

Araújo, D. F., \& Ramos, M. C. P. (2014). Empregabilidade do profissional em turismo na hotelaria Brasil/Portugal. The overarching issues of the european space: the territorial diversity of opportunities in a scenario of crisis. Porto: Faculdade de Letras da Universidade do Porto.

Bardin, L. (2009). Análise de conteúdo. Lisboa: Edições 70.

Brasil. Lei $n^{\circ}$ 9. 394, de 20 de dezembro de 1996. (1996). Estabelece as diretrizes e bases da educação nacional - LDB. Recuperado de http://portal.mec.gov.br/arquivos/pdf/ldb.pdf

Brasil. Lei $n^{o}$ 10.172, de 9 de janeiro de 2001. (2001). Aprova o Plano Nacional de Educação e dá outras providências. Recuperado de http://www.planalto.gov.br/ccivil_03/leis/leis_2001/110172.htm

Brasil. Ministério da Educação. Conselho Nacional de Educação. (2001). Parecer CNE/CES $N^{o} 583 / 2001$. Recuperado de http://portal.mec.gov.br/cne/arquivos/pdf/pces1210_01.pdf

Correia, L. M. M., Salgado, M. A. B., \& Costa, C. M. M. (2017). Ensino superior em hotelaria: Estágio curricular em licenciatura. Revista Turismo \& Desenvolvimento, 27/28, 1785-1795.

Diniz, R.V., \& Goergen, P. L. (2019). Educação Superior no Brasil: panorama da contemporaneidade. Revista da Avaliação da Educação Superior, Campinas, 24(3), 573-593.

Gatti, B. A. (2012). Grupo focal na pesquisa em ciências sociais e humanas. Brasília: Liber Livro editora.

Goergen, P. (2000). A crise de identidade da universidade moderna. In: Santos Filho, J. C. \& Moraes, S. E. (Orgs.). Escola e Universidade na Pós-Modernidade. Campinas/ São Paulo: Mercado de Letras/FAPES.

Gomes, A. A. (2005). Apontamentos sobre a pesquisa em educação: usos e possibilidades do grupo focal. EccoS Revista Científica, 275-290.

Gomes, A. (2008). Apontamentos sobre a pesquisa em educação: usos e possibilidades do grupo focal. EccoS - Revista Científica, 7(2), 275-290.

Gondim, S. M. G. (2002). Perfil profissional e mercado de trabalho: relação com formação acadêmica pela perspectiva de estudantes universitários. Estud. psicol. (Natal), Natal, 7(2) 299-309.

Instituto Nacional de Estudos e Pesquisas Educacionais Anísio Teixeira - INEP. (2018).

Sinopse estatística da educação superior. Recuperado de

http://inep.gov.br/web/guest/sinopses-estatisticas-da-educacao-superior

Mancebo, D., Silva Junior, J. R., \& Schugurensky, D. (2016). A educação superior no Brasil diante da mundialização do capital. Educ. rev., Belo Horizonte, 32(4), 205-225. 
Melo, R., \& Devile, E. (2015). Inovação e interdisciplinaridade no ensino superior em Turismo. In: Gonçalves, S., Almeida, H., \& Neves, F. (Orgs.). Pedagogia no ensino superior. Coimbra. Recuperado de

https://www.researchgate.net/publication/315660960_Inovacao_e_Interdisciplinaridade_no_E nsino_Superior_em_Turismo

Mendonça, I., \& Gomes, M. F. (2016). Grupo focal como técnica de investigação qualitativa na pesquisa em educação. Atas - Investigação Qualitativa em Educação (CIAIQ2016), 1, [429-438].

Menezes, P. D. L., \& Cavalcanti, D. R. (2020). Ensino superior e formação profissional em hotelaria: estudo de caso do Curso de Bacharelado em Hotelaria da UFPB. Revista Iberoamericana de Turismo - RITUR, 10(2).

Menezes, P. D. L., \& Teixeira, C. R. (2020). As representações sociais do bacharel em turismo: Formação, conhecimento e identidade. Tur., Visão e Ação, 22(3), 533-551.

Ollaik, L. G., \& Ziller, H. M. (2012). Concepções de validade em pesquisas qualitativas. Educação e Pesquisa, 38(1), 229-242.

Pimenta, S. G. (2009). Formação de professores: identidade e saberes da docência. In: Pimenta, S. G. (Org.). Saberes pedagógicos e atividade docente. São Paulo: Cortez.

Ribeiro, N. B. (2007). Faces da universidade contemporânea. Revista da Faculdade de Educação, (7/8), 53 -68.

Rocha, A. P., Mesquita, R. B., Meira, C. M., \& Milhomem, A. L. B. (2019). A produção científica brasileira sobre hotelaria no período 2008-2017: um estudo bibliométrico. Revista Iberoamericana de Turismo - RITUR, Penedo, 9(2), 87-104.

Silva, J., \& Ramos, M. (2006). Prática pedagógica numa perspectiva Interdisciplinar. Recuperado de https://docplayer.com.br/277398-Pratica-pedagogica-numa-perspectivainterdisciplinar.html

Universidade Federal da Paraíba - UFPB. Resolução $n^{\circ}$ 12/2018. (2018). Aprova Projeto Pedagógico do Curso de Graduação em Curso de Graduação em Hotelaria. Universidade Federal da Paraíba, Paraíba. Conselho superior de ensino, pesquisa e extensão. Recuperado de https://sigarq.ufpb.br/arquivos/20200230225f432141146b849d2daaa77/Resoluo_N_12_2018.pdf

Von Linsingen, I. (2006). CTS na Educação Tecnológica: Tensões e Desafios. Núcleo de Estudos e Pesquisas em Educação Tecnológica, UFSC. Recuperado de https://www.oei.es/historico/memoriasctsi/mesa4/m04p18.pdf

\section{FORMATO PARA CITAÇÃO DESTE ARTIGO}

MENEZES, P. D. L., \& SILVA, A. L. (2021). Ensino superior em hotelaria: relação entre formação profissional e prática no mercado de trabalho. Revista de Turismo Contemporâneo, 9(2), 195-214. https://doi.org/10.21680/2357-8211.2021v9n2ID24109 